
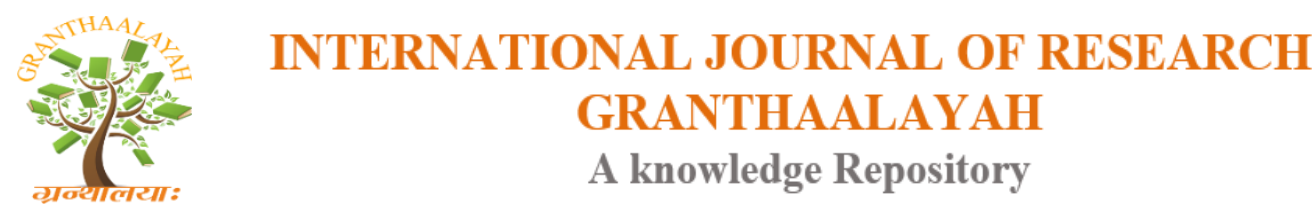

Science

\title{
CORRELATION AMONG SOME GLOBAL PARAMETERS DESCRIBING ORGANIC POLLUTANTS IN RIVER WATER: A CASE STUDY
}

\author{
Md. Serajuddin *1, Md. Aktarul Islam Chowdhury ${ }^{\mathbf{1}}$, Tahmina Ferdous ${ }^{2}$ \\ ${ }^{1}$ Department of Civil \& Environmental Engg. (CEE), Shahjalal University of Science \& \\ Technology (SUST), Sylhet 3114, Bangladesh \\ ${ }^{2}$ SUEZ International (Bangladesh Branch), Dhaka 1000, Bangladesh
}

\begin{abstract}
Organic matter in drinking water is determined by applying indirect determination methods used for quantitative measurements such as total organic carbon (TOC), chemical oxygen demand (COD), and biochemical oxygen demand (BOD). As a relatively less sophisticated and faster method ultraviolet absorption of water at $254 \mathrm{~nm}$ wavelength (UV254) is being now utilized in many countries to determine the organic matter in water. Because the UV254 absorbance parameter is proportional to the concentration of organics in the water in many research it is found that most natural water sources have a good correlation between, for example, TOC and UV254 absorption, and COD and UV254 absorption. Similarly, a definite correlation between the COD and BOD under certain conditions was reported in the literature. This study is aimed to establish the correlations among the parameters namely UV254, COD, BOD5, TOC, DOC (Dissolve organic carbon) for the river Sitalakhya, a specific surface water, which is the raw water source of the largest surface water treatment plant in Dhaka, Bangladesh. It is revealed that there is a very strong correlation between TOC and UV254 with R2=0.86. Similarly, between BOD5 and UV254, and between COD and UV254, a strong correlation was found with coefficient of determination, $\mathrm{R} 2$ value respectively 0.93 and 0.87 . All other coefficients also indicate highly significant linear correlations.
\end{abstract}

Keywords: Biochemical Oxygen Demand; Chemical Oxygen Demand; Coefficient of Determination; Total Organic Carbon; Ultraviolet Absorption of Water At $254 \mathrm{Nm}$ Wavelength; Sitalakhya River.

Cite This Article: Md. Serajuddin, Md. Aktarul Islam Chowdhury, and Tahmina Ferdous. (2018). "CORRELATION AMONG SOME GLOBAL PARAMETERS DESCRIBING ORGANIC POLLUTANTS IN RIVER WATER: A CASE STUDY." International Journal of Research - Granthaalayah, 6(7), 278-289. https://doi.org/10.29121/granthaalayah.v6.i7.2018.1308.

\section{Introduction}

From the dawn of civilization, mankind has pursued safe water and as a consequence the water treatment technologies have gradually flourished. The history of water treatment started with the 
effort of removal of turbidity from the raw water. The aesthetic was the main concern of public perception regarding the acceptability of water for drinking and household. With the passage of time water domain has been changing. Advances in the development of civilization have also advances industrialization and urbanization. As an inevitable corollary, it has changed the raw water quality regime over time \& space and thus the water treatment phenomenon. Water has progressively being characterized in terms of physical, chemical, and biological composition to facilitate management. Depending on the level of pollutants and local regulations; physical, chemical and/or biological treatment is used to make it useable.

Nowadays, oxygen-demanding pollutants are widely prevalent in the surface water which is being used for harnessing water for the ultimate use of households after treatment (Khaled et al., 2014). Organics in water is major oxygen consuming pollutant. Organic matter has to be removed from raw water harnessed for drinking due to:

1) negative effect on drinking water quality (colour, taste, and odour);

2) increased doses of coagulant and disinfectant;

3) negative impact of disinfection by-products on human health;

4) absorption of heavy metals by organic matters.

The most common technologies used for organics removal are coagulation, settling and filtration, ion exchange, membrane filtration and various oxidation processes (Ramunè et al., 2012).

The pollution of the water is frequently described using aggregate parameters, sometimes called sum parameters (Werner 2014), such as the chemical oxygen demand (COD), biochemical oxygen demand (BOD), total organic carbon (TOC) or the spectral absorption coefficients (SAC). The organic carbon in water and wastewater is composed of a variety of organic compounds in various oxidation states. Some of these carbon compounds can be oxidized further by biological or chemical processes, and the BOD and COD may be used to characterize these fractions. However, the BOD method is frequently replaced by the COD method due to problems of repeatability and inhibition by commonly occurring ions and compounds; also COD method results in the production of hazardous wastes including mercury and hexavalent chromium, sulphuric acid, silver and other hazardous materials, depending on the method used. Biochemical and chemical oxygen demand measurements have been used for over 100 years to qualify and quantify contamination in municipal and industrial wastewater as well as surface water quality. COD is the total measurement of all chemicals (organics \& in-organics) in the water/wastewater; BOD is a measure of, the amount of oxygen that requires for the bacteria to degrade the organic components present in water/wastewater (GE Power, 2016). Unlike BOD or COD, TOC is independent of the oxidation state of the organic matter and does not measure other organically bound elements, such as nitrogen and hydrogen, and inorganic that can contribute to the oxygen demand measured by BOD and COD.

The COD effectively is a measured effort the amounts of electrons available in the organic carbon for reduction of oxygen to water. TOC is the amount of carbon. The ratio is, therefore, a measure for the degree of reduction of the carbon compounds. According to the specific definition of COD -measure the amount of organic compound which oxidized to $\mathrm{CO}_{2}$, similarly TOC - measures the amount of carbon bound to an organic compound, hence the relation between COD and TOC are supposed to be directly proportional to each other. 
Biochemical Oxygen Demand, currently a five-day laboratory test labeled $\mathrm{BOD}_{5}$, is one of the most broadly used parameters for water \& wastewater quality in the world and the standard for municipal water \& sewage treatment. COD, typically a two-hour test, is more widely used in industrial applications. Often, both of these laboratory methods are measured, recorded and compared over time. TOC analysis is a well-known analytical method used in diverse water and municipal and industrial wastewater quality applications. There are multiple TOC measurement methods and technologies available in the laboratory and online configurations, and typical analytical times are 3-10 minutes depending on the mode of analysis. TOC analysis is faster and more accurate than either oxygen demand method and is a direct measurement of the organic load. The speed of analysis and online operation of TOC instruments provide advantages over oxygen demand measurements, providing near real-time analysis for event detection and integrated process control. Additionally, TOC is a direct measure of the quantity of organics in the water, whereas COD and BOD are indirect measurements (Chihoon et al., 2016; CNRS, 2006; Katarzyna et al., 2006; Waziri, 2010).

It is now not very uncommon in the world that many organization especially municipal sewage and industrial wastewater plants are conducting short-term and long-term studies to determine the correlation between organic pollutants and oxygen demand (Ramanand, 2003; Khaled, 2014). If a repeatable empirical relationship is established between TOC and BOD or COD, then TOC can be used to estimate the accompanying BOD or COD. To insure the practical capability, this relationship must be established independently for each set of matrix conditions, such as various points in a treatment process.

According to the Government of India Central Pollution Control Board (CPCB) under the Ministry of Environment \& Forests: "...based on the laboratory validation as regards to the observed ratio of TOC: BOD \& TOC: COD a correlation factor is established... In the field TOC is monitored online... Based on repeatable empirical relationship established between TOC, BOD or COD for a specific waste water source accompanying BOD or COD can be estimated from the recorded TOC values". The CPCB also specifies that the correlation must be established based on the sample matrix and validated periodically $(\mathrm{CPCB}, 2014)$. Since different parameter indicating organic pollution and oxygen demand methods are inherently different, the historical concern with correlation is the stability of the relationship over time due to any changes in the ecology of the stream(s). The variability of organics overtime could alter the mathematical relationship to oxygen demand. The sample matrix, particulate or solids composition, viscosity and turbidity can influence the correlation factor over time (CPCB, 2014; GE Power, 2016).

According to a HACH company document which dealing with wastewater in airport, experience shows that the parameters behave similarly such that correlations between the individual summing parameter can be used for specific water sample. A valid relationship has been established by Dubber, D et al. (Haoyu, 2013). via examining the replacement of COD with TOC for general monitoring by comparing the relationship between the results of TOC, BOD and COD tests performed on influent and effluent samples of 11 wastewater treatment plants. The study showed significant linear relationships between TOC, COD andBOD 5 in influent domestic and municipal wastewaters, but only between COD and TOC in treated effluents. While all these linear relationships been computed, it is not saying that TOC measurement can replace BOD and COD testing. In some cases TOC, however, can be possibly used as a replacement of BOD and COD 
values (Waziri, 2010). Similar research has been done, and the correlation between TOC and DOC was generated in the surface water layer at Lake Isąg, Poland (Katarzyna, 2006). It was concluded that it is possible to build a DOC-TOC relationship model for measurements of TOC and DOC parameters, and that suggest organic carbon from multiple sources is likely to have a clear DOCTOC relationship for a specific river (Haoyu, 2013).

Using the databases of the Regional Water Authorities (Agences de l'Eau) relations have been sought for between the total organic carbon TOC content and COD for several main French rivers, order to assess the complementary of both parameters. Linear relations have been found with reasonable coefficients of determination (>0.45) over whole watercourses such as Rhône River, Saône River and Marne River, but not on whole watershed (Rhône River watershed for example) (CNRS 2010). Correlations between TOC and COD are defined in the German waste water ordinance $(\mathrm{AbwV})$ also and can be determined for each substance.

The analyses as stated above require expensive devices, harmful chemical reagents, and are timeconsuming. Standard water quality tests are inconvenient during start-up or reconstruction of drinking water treatment plants as samples need to be transported to a laboratory and no on-line measurements on plant performing efficiency are available. For practical purposes, less sophisticated and faster methods to determine organic matter are felt required. One of the methods nowadays utilized is the ultraviolet absorption of water at $254 \mathrm{~nm}$ wavelength $\mathrm{UV}_{254}$. It is a technically simple and fast method for determining the organic matter, requiring neither expensive measurement equipment nor chemical reagents. The $\mathrm{UV}_{254}$ water quality parameter is a measurement of the absorbance of light by a water sample at $254 \mathrm{~nm}$ wavelength. Absorbance measurements are very common in the laboratory and in the field since absorbance at a given wavelength is proportional to the concentration of any substances in the water that are known to absorb light at the given wavelength. Light at the $254 \mathrm{~nm}$ wavelength is of particular interest since it is a wavelength that is very readily absorbed by organic matter in the water. Because the $\mathrm{UV}_{254}$ absorbance parameter is proportional to the concentration of organics in the water most natural water sources such as raw water for drinking water and municipal wastewater have a good correlation between, for example, TOC and $\mathrm{UV}_{254}$ absorption, and COD and $\mathrm{UV}_{254}$ absorption (Chihoo et al.,2016; Haoyu et al,2013; Heloise, 2014; Liyang et al., 2014; Ramune et al., 2012; Shamsad et al., 2014; Tanju et al., 2002; Tasnim et al., 2015; Wendy et al., 2010) .

The correlation factor will depend on the particular organic water quality parameter being correlated to and will also depend on the matrix of organics being measured. This means that correlations are site and application specific, and so the correlation factor must be determined at the measurement site (US-IST 19, 2010).

Thus, it is possible to correlate BOD (Biochemical Oxygen Demand) with COD (Chemical Oxygen Demand) and TOC (Total Organic Carbon) and $\mathrm{UV}_{254}$ and other complementariness.

There is no such study on correlation of water quality parameters on any Bangladeshi river water found in the literature. The present study might be the first of its kind, especially with river water of the capital city. 


\section{Objective of the Study}

The objective of this study is to establish the correlations among these parameters namely $\mathrm{UV}_{254}$, COD (Chemical Oxygen Demand), BOD 5 (Biochemical Oxygen Demand), TOC (Total Organic Carbon), DOC (Dissolve organic carbon) for a specific surface water source, river Sitalakhya that is the source of the largest surface water treatment plant in Dhaka, Bangladesh. Thus knowing one parameter one can estimate other parameters complimentarily among themselves, specially knowing $\mathrm{UV}_{254}$ one can estimate any other organic pollution parameters which might save time, money and can give instantaneous water quality information as required. This study is limited to water of the Sitalakhya at the intake of the Dhaka water treatment plant.

\section{Materials and Methods}

\section{Study Area}

The study area is Dhaka the capital city of Bangladesh with a population of around fifteen million located in the central part of Bangladesh. Dhaka has a tropical savanna climate. The city has a distinct monsoonal season, with an annual average temperature of $26{ }^{\circ} \mathrm{C}\left(79{ }^{\circ} \mathrm{F}\right)$ and monthly means varying between $19^{\circ} \mathrm{C}\left(66^{\circ} \mathrm{F}\right)$ in January and $29^{\circ} \mathrm{C}\left(84^{\circ} \mathrm{F}\right)$ in May, sometimes reaching to $40^{\circ} \mathrm{C}$. Approximately $87 \%$ of the annual average rainfall of 2,123 millimeters (83.6 inches) occurs between May and October. Dhaka is located at $23^{\circ} 42^{\prime} \mathrm{N} 90^{\circ} 22^{\prime} \mathrm{E}$, on the banks of the Buriganga river and surrounded by other peripheral rivers. The largest treatment plant of the country is situated beside the river Sitalakhya in the eastern periphery of Dhaka city at Latitude N $23^{\circ} 43^{\prime}$ 11.25" \& Longitude E $90^{\circ} 26^{\prime} 14.25^{\prime \prime}$. The raw water from the intake of this plant was collected and used for this study (Serajuddin et al., 2018).

\section{Sample Collection and Analysis}

Water samples were collected from the treatment plant intake. Samples were collected in clean plastic cans of 2 lit capacities for physic-chemical analysis. The collected samples were transferred to the laboratory of the plant, by following the precautions laid by standard methods (APHA, 1995). $\mathrm{pH}$, DO, temperature, turbidity was determined within the field of collection, the other parameters like $\mathrm{COD}, \mathrm{DO}, \mathrm{BOD}_{5}, \mathrm{TOC}, \mathrm{DOC}, \mathrm{UV}_{254}$, Turbidity, etc. were analyzed in the laboratory within the stipulated period.

\section{Results and Discussions}

The results of the analysis for all the parameters used as test data are presented in Table 1 and relationships between the parameters in form of scatter gram are shown in Fig. 1-9. The regression analysis carried out to relate $\mathrm{UV}_{254}$ with BOD, COD and TOC and complimentarily with each other.

Table 1: River water quality test result

\begin{tabular}{|l|l|l|l|l|l|}
\hline Date & $\begin{array}{l}\text { Total COD } \\
\text { mg/L }\end{array}$ & $\begin{array}{l}\text { BODs } \\
\text { mg/L }\end{array}$ & $\begin{array}{l}\text { TOC } \\
\text { mg/L }\end{array}$ & UV 254 & $\begin{array}{l}\text { DOC } \\
\text { mg/L }\end{array}$ \\
\hline January 22, 2011 & 25 & 15.11 & 21 & 0.6 & 8 \\
\hline February 15, 2011 & 38 & 21.1 & 22.95 & 0.72 & 7.8 \\
\hline February 20, 2011 & 47 & 27.82 & 24 & 0.8 & 10 \\
\hline February 28, 2011 & 62 & 40 & 28 & 0.9 & 12 \\
\hline
\end{tabular}




\begin{tabular}{|l|l|l|l|l|l|}
\hline March 01, 2011 & 80 & 50 & 30.5 & 1.26 & 16 \\
\hline March 05, 2011 & 84 & 58 & N. A & 1.3 & N. A \\
\hline March 15, 2011 & 63 & 32.7 & 24.1 & 0.915 & 9 \\
\hline March 28, 2011 & 59 & 20 & N. A & 0.8 & N. A \\
\hline April 02, 2011 & 57 & 34.5 & 26.6 & 0.967 & 12 \\
\hline April 13, 2011 & 66 & 39.8 & 27.5 & 1.08 & 13 \\
\hline April 26, 2011 & 63 & 44 & N. A & 1.1 & N.A \\
\hline
\end{tabular}

From Table: 1 it is demonstrated TOC concentration ranges from $21 \mathrm{mg} / \mathrm{L}$ to $30.5 \mathrm{mg} / \mathrm{L}$. There is no guideline value of TOC for raw water in Bangladesh. As per any international standard this observed concentration are very high. The investigation of correlation between the total organic carbon and UV absorption of the surface water at $254 \mathrm{~nm}$ wavelength was performed. Fig. 1 presents linear correlation between $\mathrm{TOC}$ and $\mathrm{UV}_{254}$, its mathematical expression being $\mathrm{TOC}=$ 13.94UV $\mathrm{UV}_{254}+12.95 ; \mathrm{R}^{2}=0.86$ which means that TOC and $\mathrm{UV}_{254}$ correlation is very strong. The obtained result allows a clear assumption that if the high $\mathrm{UV}_{254}$ are found in water, then high TOC concentration will be also expected. And from $\mathrm{UV}_{254}$ measurements the TOC concentration could be calculated in the Sitalakhya water.

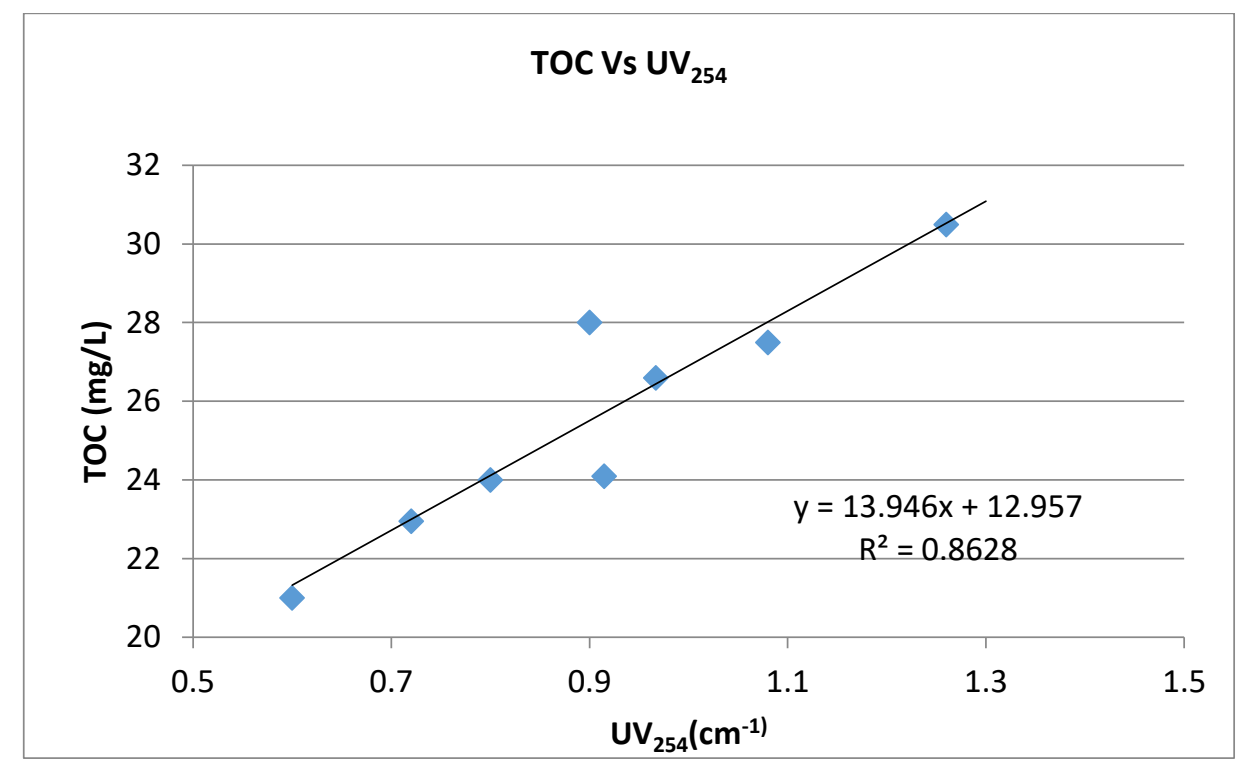

Figure 1: Correlation between TOC vs UV 254

Fig. 2 indicates $\mathrm{BOD}_{5}$ values in the tested river water. The concentration values ranges from 15 to $58 \mathrm{mg} / \mathrm{L}$ indicating much polluted water. The allowable maximum concentration for a best practice-based classification water as per Bangladeshi guideline is $6 \mathrm{mg} / \mathrm{L}$. 


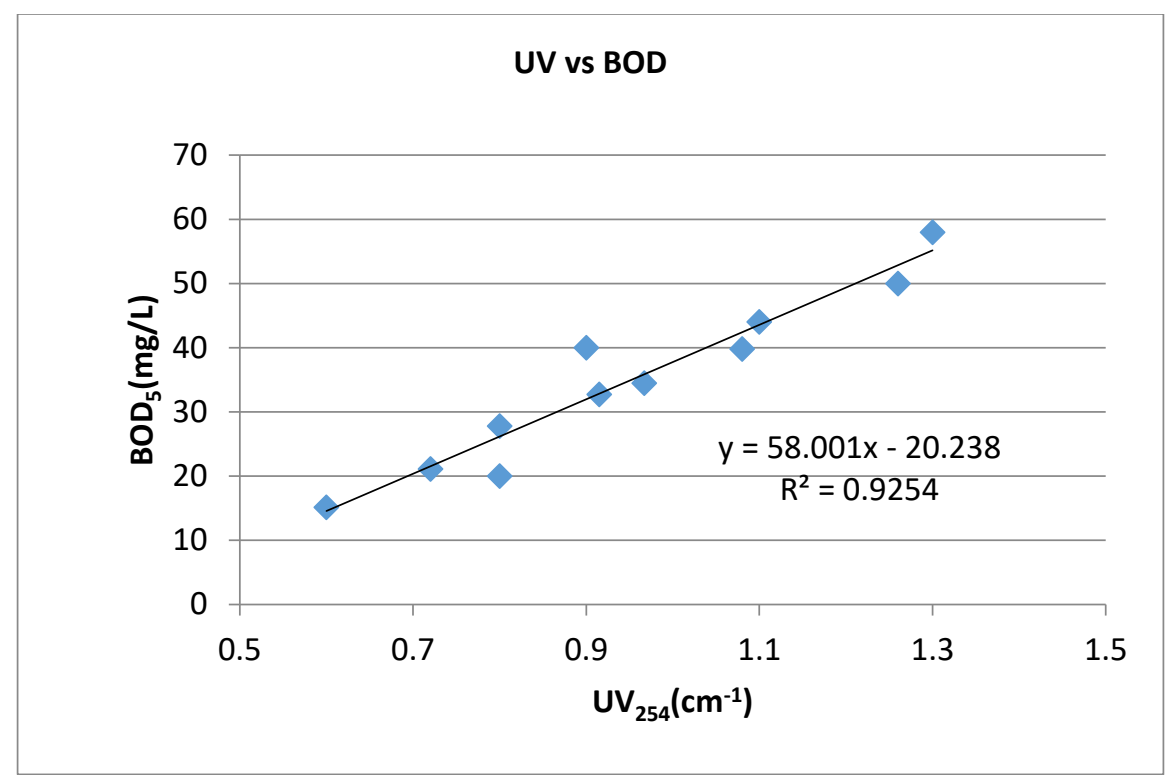

Figure 2: Correlation between BOD5 vs UV254

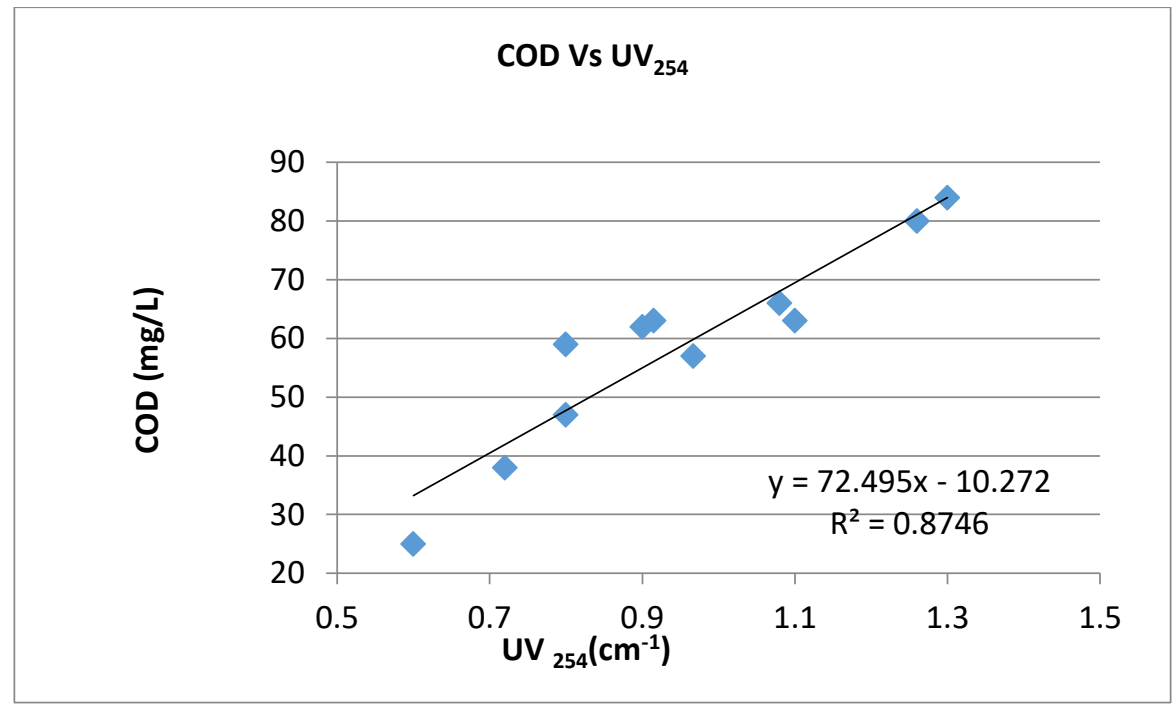

Figure 3: Correlation between COD vs $\mathrm{UV}_{254}$

Presented linear correlation between $\mathrm{BOD}_{5}$ and $\mathrm{UV}_{254}$, is expressed by equation $\mathrm{BOD}_{5}=58.00$ $\mathrm{UV}_{254}-20.23$; and its coefficient of determination is equal to $\mathrm{R}^{2}=0.925$. The obtained results show that $\mathrm{BOD}_{5}$ and $\mathrm{UV}_{254}$ correlation is very strong even stronger compare to TOC and $\mathrm{UV}_{254}$. Similarly Fig. 3 presented COD values in the tested water against UV 254. The linear correlation between COD and $\mathrm{UV}_{254}$ is shown by the equation $\mathrm{COD}=72.49 \mathrm{UV}_{254}-10.27$; coefficient of determination is $\mathrm{R}^{2}=0.86$. This result also shows that correlation COD and $\mathrm{UV}_{254}$ is also very strong, although a bit weaker compared to the $\mathrm{BOD}_{5}$ and $\mathrm{UV}_{254}$.

The coefficients of determination of each of the two pollution parameter with the corresponding equation are demonstrated below. All the coefficients indicate highly significant linear correlation. One can use the equations in order to obtain the desired concentration from the known concentration of a parameter. All the coefficients indicate highly significant linear correlation. 
These equations may be used to assess complimentary water quality parameter harnessed from the Sitalakhya river intake point of Dhaka water treatment plant.

Table 2: Complimentary Correlation Equations

\begin{tabular}{|c|c|c|}
\hline $\begin{array}{l}\text { Complimentary water quality } \\
\text { parameters }\end{array}$ & Correlation Equation & $\begin{array}{ll}\text { Coefficient } \\
\text { determination }\left(\mathbf{R}^{2}\right)\end{array} \quad$ of \\
\hline TOC, $\mathrm{UV}_{254}$ & \begin{tabular}{|l} 
TOC $=$ \\
$13.95 \mathrm{UV}_{254}+12.96$
\end{tabular} & $\mathrm{R}^{2}=0.86$ \\
\hline $\mathrm{BOD}_{5}, \mathrm{UV}_{254}$ & $\begin{array}{l}\mathrm{BOD}_{5}=58.00 \quad \mathrm{UV}_{254}- \\
20.23\end{array}$ & $\mathrm{R}^{2}=0.93$ \\
\hline $\mathrm{COD}, \mathrm{UV}_{254}$ & $\begin{array}{lll}\mathrm{COD}= & 13.95 & \mathrm{UV}_{254} \\
+12.96 & & \\
\end{array}$ & $\mathrm{R}^{2}=0.86$ \\
\hline COD, BOD5 & $\begin{array}{l}\mathrm{COD}=1.151 \mathrm{BOD}_{5}+ \\
18.43\end{array}$ & $\mathrm{R}^{2}=0.81$ \\
\hline BOD5, DOC & $\begin{array}{l}\mathrm{BOD}_{5}=3.703 \mathrm{DOC}- \\
8.015\end{array}$ & $\mathrm{R}^{2}=0.87$ \\
\hline DOC, UV254 & $\begin{array}{l}\mathrm{DOC}=12.62 \mathrm{UV}_{254}- \\
0.455\end{array}$ & $R^{2}=0.86$ \\
\hline TOC, DOC & $\begin{array}{l}\mathrm{TOC}=1.060 \mathrm{DOC}+ \\
13.94\end{array}$ & $\mathrm{R}^{2}=0.92$ \\
\hline COD, TOC & $\begin{array}{l}\mathrm{COD}=5.136 \mathrm{TOC}- \\
76.63 ;\end{array}$ & $\mathrm{R}^{2}=0.84$ \\
\hline COD, DOC & $\begin{array}{l}\mathrm{COD}=5.292 \mathrm{DOC}- \\
3.338\end{array}$ & $R^{2}=0.73$ \\
\hline
\end{tabular}

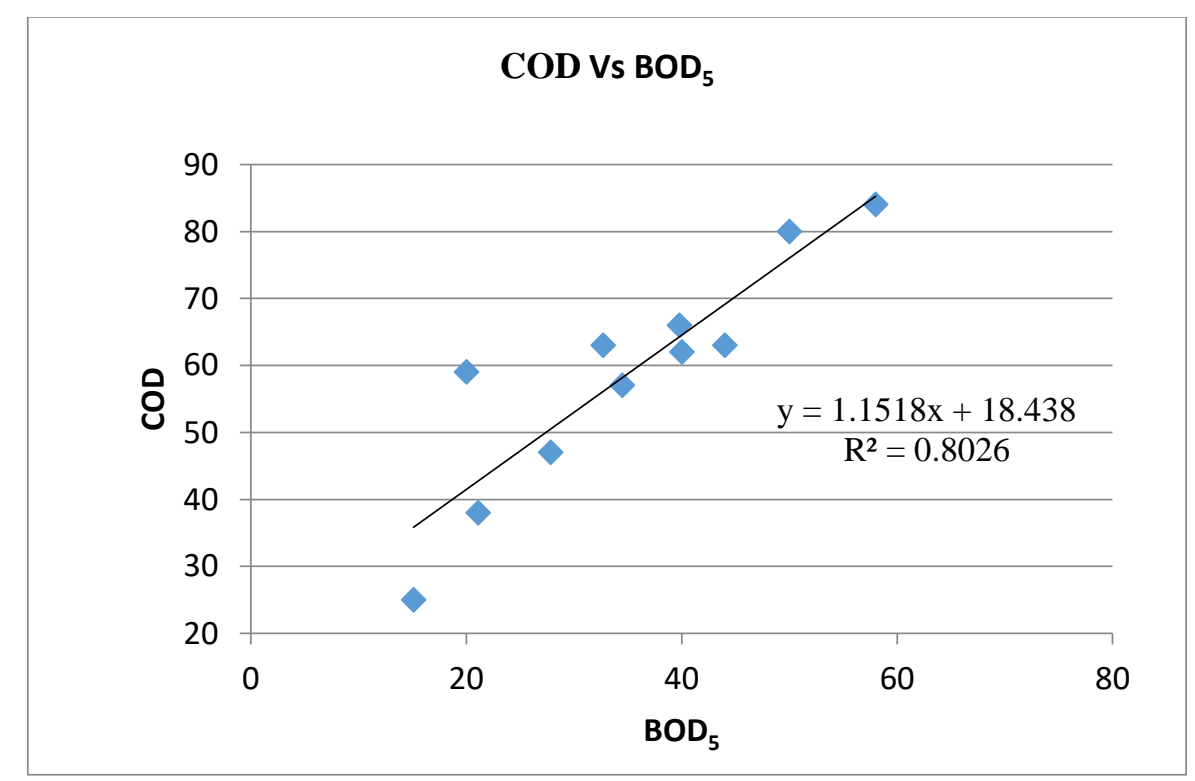

Figure 4: Correlation between COD vs BOD5 


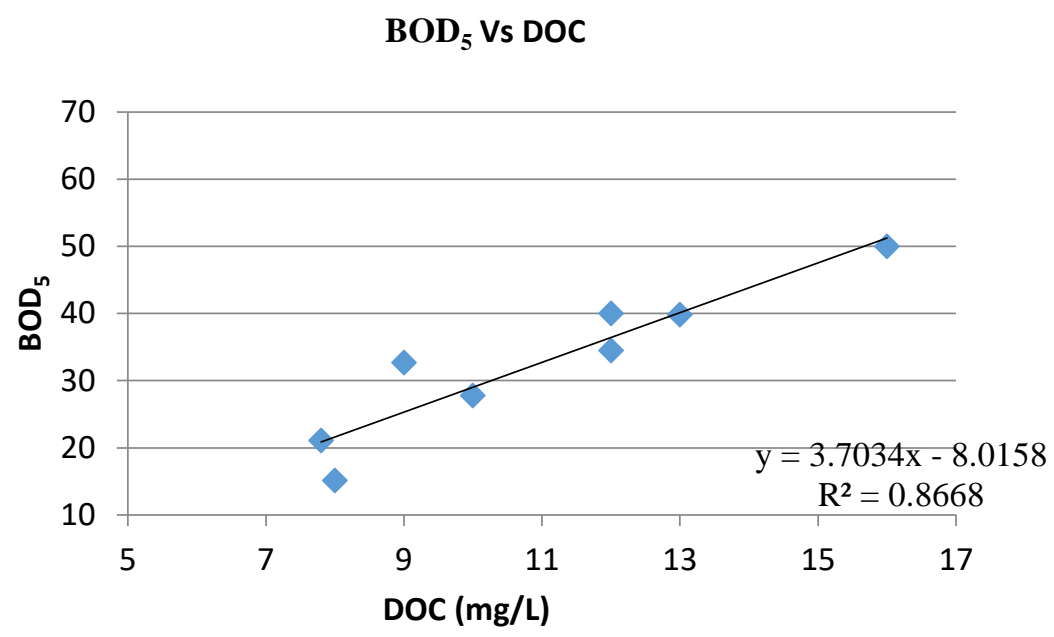

Figure 5: Correlation between $\mathrm{BOD}_{5}$ vs DOC

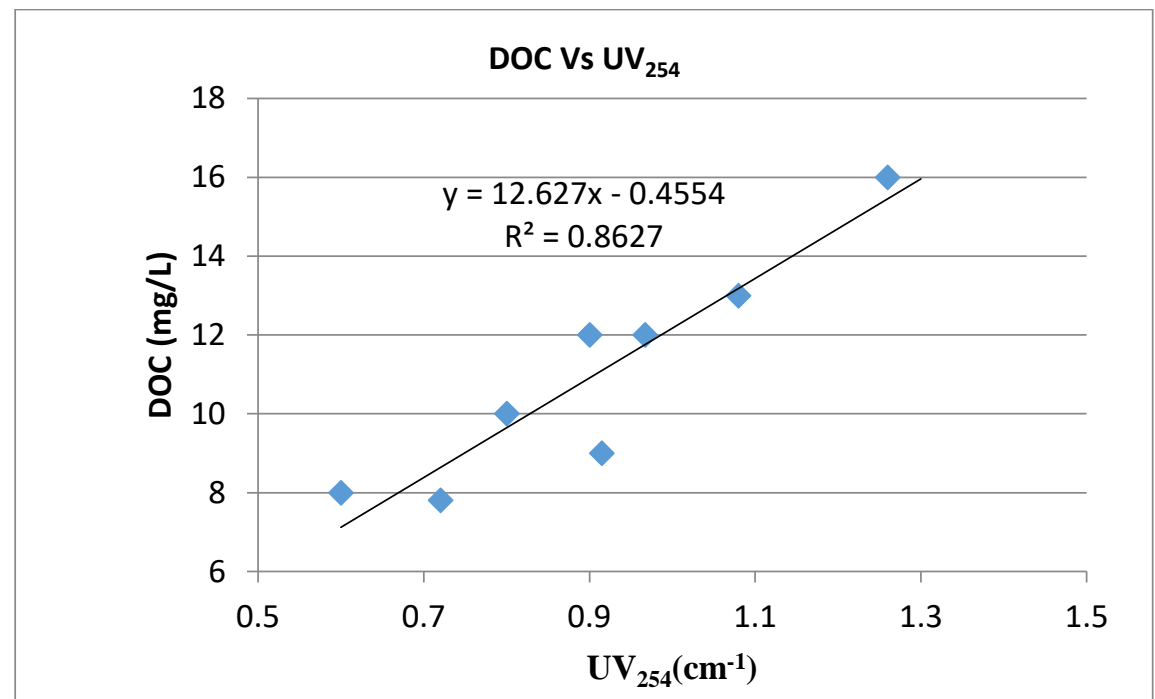

Figure 6: Correlation between DOC vs $\mathrm{UV}_{254}$

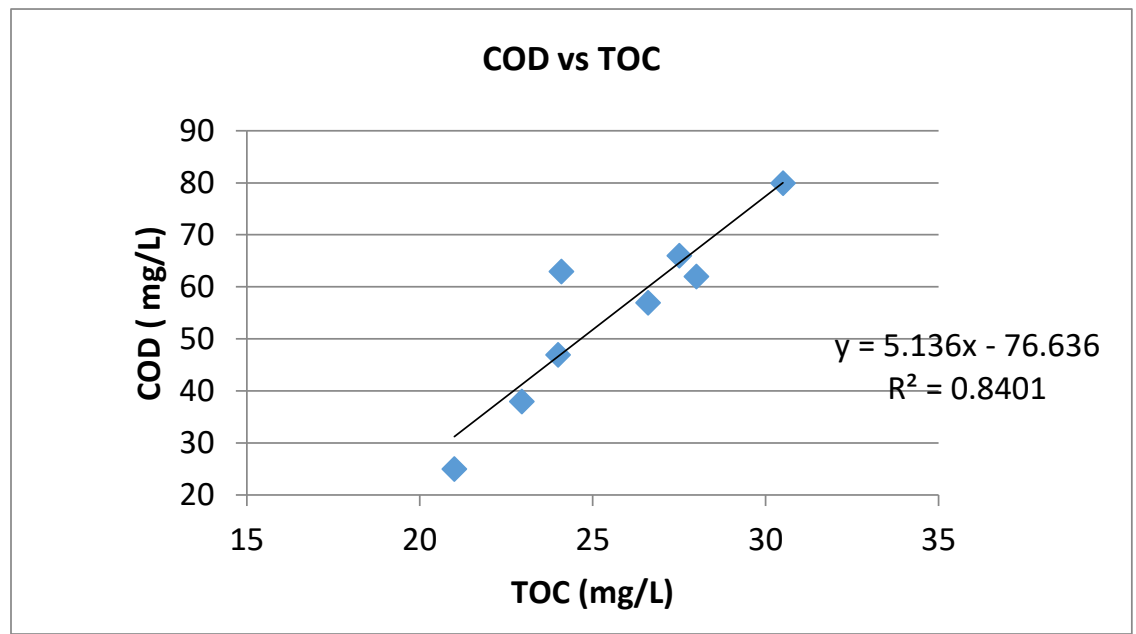

Figure 7: Correlation between COD vs TOC 


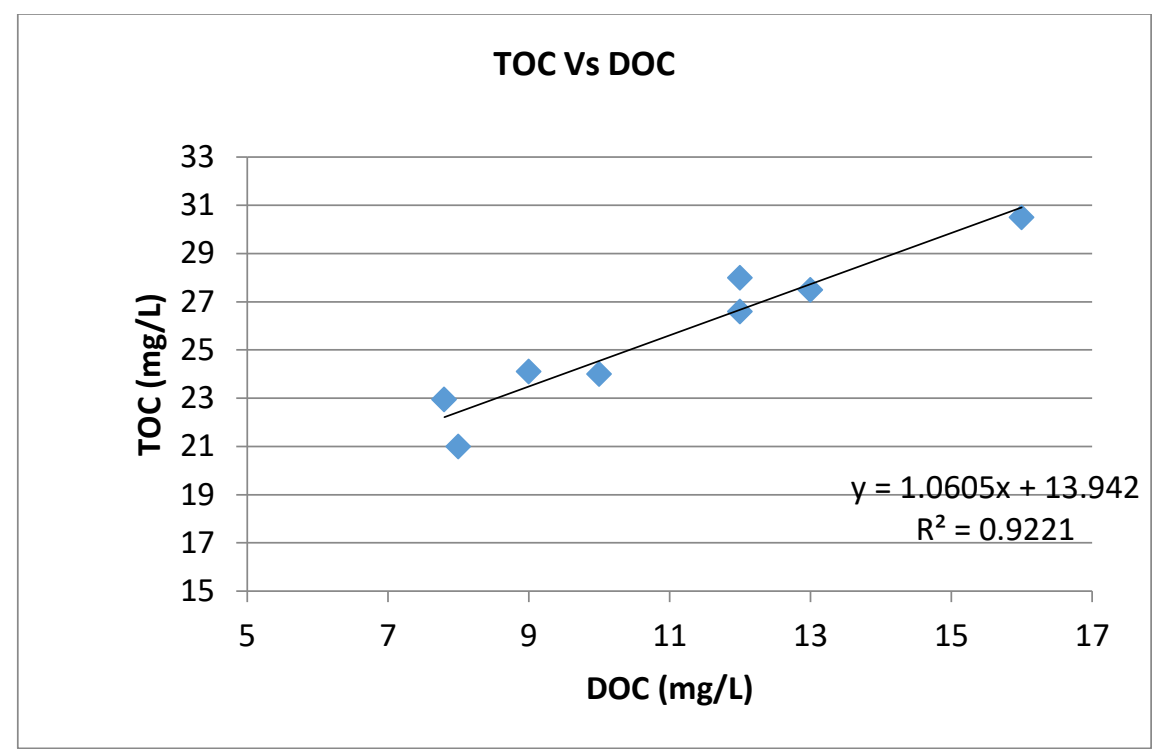

Figure 8: Correlation between TOC vs DOC

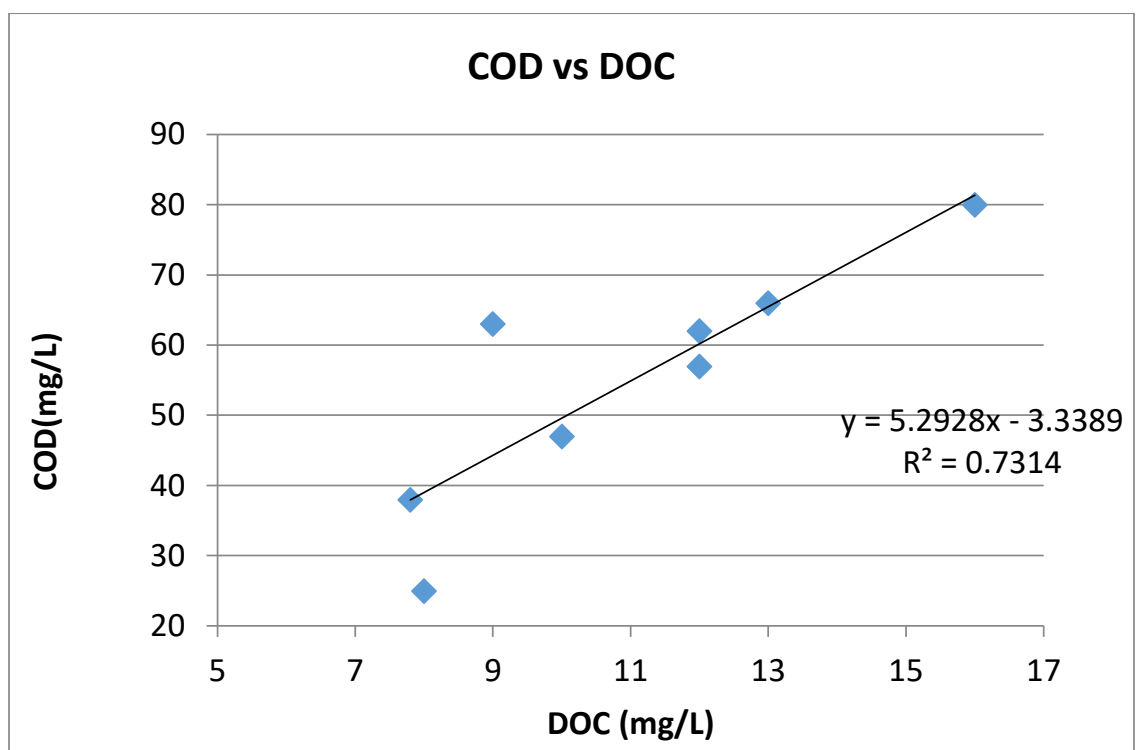

Figure 9: Correlation between COD vs DOC

It is to be noted that when COD is zero BOD should be zero, it must not be negative. It is same for many other criteria. Usually COD/BOD ratio is taken into consideration in such cases.

It may be mentioned that the experiment was conducted starting from the month of January up to April covering almost whole of the acute dry seasonal months of the year 2011 which gives the most polluted water quality of that year. Similar study may be taken covering a full year covering the full hydrologic cycle of a year and also taking data from a series of year. This study is site and season specific as such similar study may be continued for other location of the river as well as for longer duration of time. This might help to understand the trend of changes in the equations, if any, over time and space. 


\section{Conclusions and Recommendations}

A very highly linear correlation ship $\left(\mathrm{R}^{2}=0.862\right)$ is illustrated between absorbance $(254 \mathrm{~nm})$ and concentration of DOM measured in terms of TOC in water from Sitalakhya river at the intake of Dhaka plant. Similar very highly linear even more strong correlation ship $\left(R^{2}=0.925\right)$ is illustrated between absorbance $(254 \mathrm{~nm})$ and BOD $_{5}$ in water from Sitalakhya river at the intake of Dhaka plant.

Furthermore, correlations among the parameters taken under this study namely $\mathrm{UV}_{254}$, COD (Chemical Oxygen Demand), BOD 5 (Biochemical Oxygen Demand), TOC (Total Organic Carbon), DOC (Dissolve organic carbon) complimentarily are very good ( $\mathrm{R}^{2}$ ranging from 0.80 to 0.92). Thus knowing one parameter one can estimate other parameters complimentarily among themselves.

The correlations of $\mathrm{COD}, \mathrm{BOD}_{5}, \mathrm{TOC}$ and or DOC with absorbance indicate that this method might be useful for estimation of concentration of DOM in water with confidence. This method has benefit over general techniques for estimation of DOM concentrations with less time consumption.

It is to be remembered that this study has been done for a specific surface water source, river Sitalakhya that is the source of the largest surface water treatment plant in Dhaka, Bangladesh and for the dry season of a year. The relationship will be different for every water source i.e. the same correlation from one site could not be used in another site. Similar study may be taken for a full year covering the full hydrologic cycle of a year and also taking data from a series of year for this point as well as different reaches of the same river.

\section{Acknowledgements}

A number of Engineers and technical staffs from the Dhaka plant and a number of experts from $\mathrm{M} / \mathrm{s}$ SUEZ International, the constructor of Dhaka Plant project, especially Dr. Jean Claude Seropian, assisted in the study and this co-operation are greatly appreciated.

\section{References}

[1] Chihoon, K; Joo Beom, E; Soyoun, J; Taeksoo, J. (2016). "Detection Of Organic Compounds In Water By An Optical Absorbance Method. "Sensors, Vol.16, No.61, Pp. (Doi:10.3390/S16010061 Http://Www.Mdpi.Com/Journal/Sensor)

[2] Cpcb. (2014). Guidelines for Online Continuous Monitoring System for Effluents, Guidelines for Real-Time Effluent Quality Monitoring System.” Central Pollution Control Board, Delhi, India, Page12. (Http://Mpcb.Gov.In/Images/Finalguidelinse.Pdf.)

[3] Cnrs. (2006). "Relations Between Organics Carbon And Chemical/Biological Oxygen Demands In French Rivers. ” Laboratoire Réactions Et Génie Des Procédés, Université De Lorraine, Posters - D5 - Qualité D'eau \& Ecosystème / Water Quality \& Ecosystems, Grandville, Bp 20451, 54001, Nancy, France.

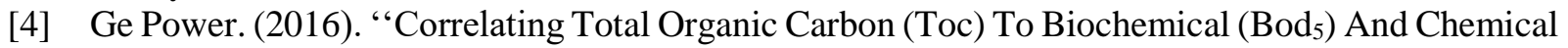
Oxygen Demand (Cod).'W Water and Process Technology. Application Note.

(Https://Www.Researchgate.Net/File.Postfileloader.Html. (02 July 2018). 
[5] Haoyu, Z. (2013). "Rapid Determination of Dissolved Organic Carbon by Persulfate Oxidation Vial and Uv/Vis Spectrophotometer'. M.Sc. Thesis, Oklahoma State University, Usa.

[6] Heloise, G. K; Cristova. V. S. F; Ju' Lio, C.R.Z; Monica, F; Amaral. (2014). "Applicability of Fluorescence and Absorbance Spectroscopy to Estimate Organic Pollution in Rivers." Environmental Engineering Science, Vol.31. No. 12, Pp. 653-663.

[7] Katarzyna, P; Mariusz, T; Jolanta, G. (2006). "Relationship Between Organic Carbon and Other Measures of Organic Matter in The Waters of Lake Isąg'. Limnological Review, Vol.6, No. Nil, Pp. 233-238.

[8] Khaled, Z. A and Ginam, H. (2014). "Correlation Between Biochemical Oxygen Demand and Chemical Oxygen Demand for Various Wastewater Treatment Plants in Egypt To Obtain the Biodegradability Indices. "International Journal of Sciences: Basic and Applied Research (Ijsbar), Vol. 13, No 1, Pp. 42-48.

[9] Liyang, Y; Hyun-Sang, S; Jin Hur. (2014). "Estimating the Concentration and Biodegradability of Organic Matter In 22 Wastewater Treatment Plants Using Fluorescence Excitation Emission Matrices and Parallel Factor Analysis. "Sensors, Vol.14, No.Nil, Pp. 1771-1786; (Doi: 10.3390/S140101771).

[10] Naomi, H; Andybaker; David, W; Darren, M; Reynolds; Chris, B; Cynthia, C; Simon, B. (2007). "Can Fluorescence Spectrometry Be Used as A Surrogate for The Biochemical Oxygen Demand (Bod) Test in Water Quality Assessment? An Example from South West England." (Https://Doi.Org/10.1016/J.Scitotenv.2007.10.054get Rights and Content).

[11] Ramune, A; Mindaugas, R; Elena, Z; Valentinas, S; Alvydas, Z. (2012). "Determination of Organic Matter by Uv Absorption in the Ground Water." Journal of Environmental Engineering and Landscape Management, Vol.20, No. 2, Pp. 163-167.

[12] Ramanandbhat, M; Roopali, S; Hiremath; Vinayak, R.K. (2003). "Correlation Between Bod, Cod and Toc', Jr. Of Industrial Pollution Control.” Vol. 19, No, 2, Pp. 187 -191

[13] Serajuddin, M; Aktarul Islam Chowdhury, M; Ehteshamul, H; Tahmina, F. (2018). "Drinking Water Quality Assessment in Terms of Water Quality Index (Wqi) In Dhaka, Bangladesh 'Global Science and Technology Journal." Vol. 6, No. 1, Pp.1-16

[14] Shamshad, K; Wu, Y; Zhang, X; Liu, J; Sun, J; Hu, S. (2014). "Estimation of Concentration of Dissolved Organic Matter From Sediment By Using Uv-Visible Spectrophotometer.” Journal Of Environmental Pollution And Remediation,Vol.2,No.1,Pp.24-29

[15] Tasnim, A, (2015). "Estimation of Chemical Oxygen Demand in Wastewater Using-Vis Spectroscopy." M.Sc. Thesis, Simon Fraser University

[16] Us-Ist 19. (2014). "Correlating the Uv ${ }_{254}$ Water Quality Parameters to Other Organics." (Http://Www.Prpcess Instruments.Net/Products/Parameter/Uv 254 - Analyzer/)

[17] Waziri, M; And Ogugbuaja, V. (2010). "Interrelationships Between Physicochemical Water Pollution Indicators: A Case Study of River Yobe-Nigeria." American Journal of Scientific and Industrial Research', Vo.1, No.1, Pp. 76-80

[18] Wendy, C.Q; Alison, F; Roy, Z; Evan, W. C; Michele, A. Csiro. (2015). "Evaluation of Organic Matter Concentration in Winery Wastewater: A Case Study from Australia Land and Water. "Griffith Laboratory, Research, Station Road, Griffith, Nsw 2680, Australia.

[19] Werner. (2018). "Bod, Cod, Toc and Tod - Sum Parameters in Environmental Analysis. "Arts, Lar Process Analysers Ag (Www.Chemeurope. Com)

*Corresponding author.

E-mail address: serajdwasa@ gmail.com 